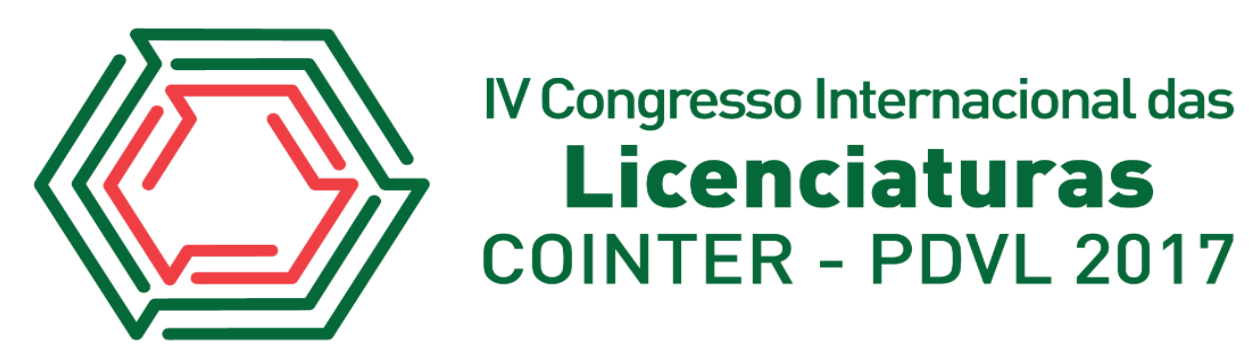

\title{
A INSERÇÃO DE ATIVIDADES PRÁTICAS NO ENSINO DE BIOLOGIA -TIPAGEM SANGUÍNEA EM SALA DE AULA
}

Apresentação: Relato de Experiência

Jardielle de Lemos Silva ${ }^{1}$; Flávia Ariane Santos de Lima²; Maria Mercia Vital da Silva ${ }^{3}$;Vanessa Poliana Batista da Silva ${ }^{4}$; Emanuel Souto ${ }^{5}$

\section{Introdução}

Uma das áreas que a Biologia tem mais despertado o interesse dos estudantes da Educação Básica é a Genética por estudar assuntos que estão cada vez mais presentes em nosso cotidiano, como o genoma, clonagem, produtos transgênicos, o uso de terapêutico das células-tronco e teste de paternidade (SILVEIRA,2008).Apesar do interesse descrito, é observado, de forma geral, que existe uma grande dificuldade discente em compreender diversos temas em genética (BONZANINI, 2011). Muitos estudantes por não conhecer as possíveis aplicações da genética, julgam a área como difícil, criando resistências que comprometem a aprendizagem. $\mathrm{O}$ objetivo deste trabalho concentra-se na descrição de um relato de experiência sobre o uso da prática demonstrativa sobre sistema $\mathrm{ABO}$, envolvendo os alunos na observação direta das reações e estimulando a reflexão sobre as conexões dos fenômenos observados na prática com as informações teóricas. O relato foi extraído da experiência vivida por futuras professoras no campo de estágio e serviu também para a reflexão coletiva sobre a necessidade e urgência de buscarmos estratégias que mobilizem a atenção, participação e protagonismo dos estudantes no processo de construção do conhecimento.

\section{Relato de Experiência}

A intervenção em questão foi realizada na Escola de Referência em Ensino Médio Professor Barros Guimarães, na cidade de Glória do Goitá - PE. Essa atividade foi planejada e executada por estagiárias da Licenciatura em Biologia do Centro Acadêmico de Vitória CAV/UFPE em duas turmas do $3^{\circ}$ ano do Ensino Médio, envolvendo cerca de 40 estudantes. De início, foi apresentada a proposta da aula teórica e estabelecido um diálogo com os alunos para resgatar os conhecimentos prévios, seguido de exposição dialogada centrada no tema: Sistema Sanguíneo. A abordagem teórica permitiu

\footnotetext{
${ }^{1}$ Licenciatura em Ciências Biológicas, UFPE- Campus Vitória de Santo Antão, jardy1@hotmail.com

${ }^{2}$ Licenciatura em Ciências Biológicas, UFPE- Campus Vitória de Santo Antão, flavia-yanka@hotmail.com

${ }^{3}$ Licenciatura em Ciências Biológicas, UFPE- Campus Vitória de Santo Antão,mercia971@live.com

${ }^{4}$ Licenciatura em Ciências Biológicas, UFPE- Campus Vitória de Santo Antão,vanessa.poliana@hotmail.com

${ }^{5}$ Professor da Universidade Federal de Pernambuco/Centro Acadêmico de Vitória (UFPE/CAV), e-mail: emanuelsouto2@globo.com
} 
explorar aspectos relacionados aos processos de transfusão de sangue, testes para determinar o grupo sanguíneo e as bases genéticas do sistema ABO. Em seguida, foi realizada uma demonstração em sala de aula de como é feito a tipagem sanguínea, com uma técnica de enfermagem, obedecendo às seguintes etapas: foi perfurado o dedo de uma das estagiárias e material coletado foi depositado nas lâminas, logo depois foi adicionado gotas de anticorpos $\mathrm{A}, \mathrm{B}$ e $\mathrm{AB}$, sendo homogeneizado na própria lâmina e em seguida analisado qual lâmina aglutinou, todos seguiram a sequência da técnica. Logo após, foi aplicado um questionário com o intuito de analisar as impressões discentes sobre o tema proposto. A aplicação do questionário permitiu mostrar que os alunos conseguiram descrever como funciona o sistema $\mathrm{ABO}$ e de como é importante saber do seu tipo sanguíneo em diversos contextos.

Imagem1: Atividade Prática Demonstrativa. Fonte: Própria

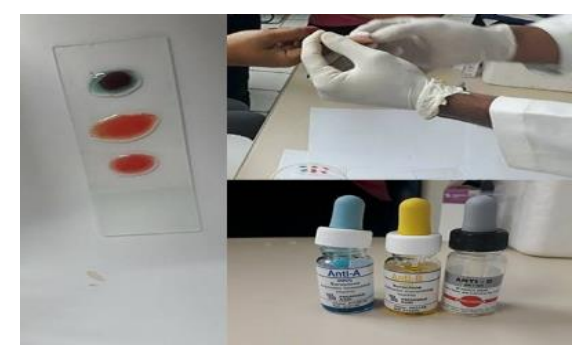

\section{Considerações}

A inserção das atividades práticas nos diferentes contextos didáticos representa uma alternativa valiosa no processo de redirecionamento do trabalho desenvolvido nas escolas. A experiência vivenciada possibilitou confirmar que estratégias de natureza prática impactam positivamente no desenvolvimento de sequências didáticas, mobilizando a atenção dos estudantes e estimulando a construção de significados para os elementos teóricos. Vale também reforçar a importância da experiência descrita na construção de competências docentes e ampliação do repertório de vivências para as futuras professoras responsáveis pelo trabalho aqui descrito.

\section{Referências}

SILVEIRA, Diego Teixeira; ZAFALON, Bruna da Silva; SOPEZKI, Maurício da Silva; MANZKE, Vitor Hugo Borba; BOBROWSKI, Vera Lucia. Aprendizagem de conceitos básicos de genética no ensino médio: avaliação preliminar. Conhecimento sem fronteiras, XVII Congresso de Iniciação Científica, $11^{\mathrm{a}} 14$ de novembro de 2008.

BONZANINI, TaitiânyKárita. Temas da Genética contemporânea e o Ensino de Ciências: que materiais são produzidos pelas pesquisas e que materiais os professores utilizam? 2011. 